\title{
TRANSACTIONS OF THE
}

INTERNATIONAL ASTRONOMICAL UNION VOL. XIVA (REPORTS 1970)

\section{REPORTS ON ASTRONOMY}


TRANSACTIONS

OF THE

INTERNATIONAL

ASTRONOMICAL UNION

VOLUME XIVA - REPORTS 
INTERNATIONAL COUNCIL OF SCIENTIFIC UNIONS INTER NATIONAL ASTRONOMICAL UNION UNION ASTRONOMIQUE INTERNATIONALE

\author{
TRANSACTIONS \\ OF THE \\ INTER NATIONAL ASTRONOMICAL UNION \\ VOLUME XIVA
}

\title{
REPORTS \\ $\mathrm{ON}$ \\ ASTRONOMY
}

Edited by

\section{CORNELIS DE JAGER}

Assistant General Secretary of the Union

PUBLISHED FOR THE INTERNATIONAL COUNCIL OF SCIENTIFIC UNIONS WITH THE FINANCIAL ASSISTANCE OF UNESCO

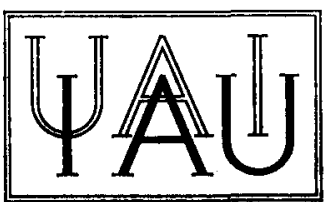

D. REIDEL PUBLISHING COMPANY/DORDRECHT-HOLLAND 1970 


\author{
Published on behalf of \\ the International Astronomical Union \\ by \\ D. Reidel Publishing Company \\ Dordrecht - Holland
}

\begin{abstract}
All Rights Reserved
Copyright 1070 by the International Astronomical Union

Unesco subvention - 1969 - DG/2.1/414/30

Library of Congress Catalog Card Number 30-10103
\end{abstract}

SBN 9027701547

Printed in The Netherlands by D. Reidel, Dordrecht 


\section{PREFACE}

The tri-annual preparation of the Reports on Astronomy is an impressive world-wide undertaking, involving not only the Presidents, Vice-Presidents and Organizing Committees of our thirty-eight Commissions, but also the greater part of the Commission members, and many other astronomers certainly more than a thousand people. These large co-operative enterprises have led in the past to the successive Draft Reports and Transactions of the IAU. These constitute a series of monumental milestones characterizing in thirteen big steps the imposing progress of our science in the last fifty years.

An important change occurs in the present Reports. Financial reasons made it impossible for the Union to keep to the tradition of first printing the Draft Reports which, prior to the General Assembly were airmailed to all IAU members, and later printed again, finally amended and corrected. The Executive Committee of the Union had to decide that the reports should be printed directly, distributed to the participating IAU members at the General Assembly, and sent later by surface mail to the other members of the Union.

Furthermore it appeared necessary to reduce the size of these Reports to slightly more than one half of that of Transactions XIIIA - the previous Reports on Astronomy. It is fully realized that these constraints made the task of the Commission Presidents and their coworkers heavier than usual. First of all, the deadline for submitting the manuscripts had to be a fairly strict one since the Reports had to be printed and bound in time, and the subsequent addition of material was no longer possible.

However, the greatest difficulty was the reduction of the size. The Executive Committee suggested Commission Presidents to achieve this by the following measures:

1. By deleting the full lists of references; these took about one third of the previous Reports. This suggestion seems justified by the recent appearance of the first issue of Astronomy and Astrophysics Abstracts, the successor to the Astronomischer Jahresbericht. This new publication gives a complete review of the astronomical literature, and appears within six to twelve months after the publication of the abstracted papers; it is more complete and certainly more up to date than would have been possible in our Reports. (We should add, however, that these restrictions were allowed to be interpreted more liberally in the case of Commission 14, where the inclusion of fairly long lists of references from fields adjacent to our science was thought to be useful.)

2. By a reduction of the contents of the Reports to the really essential matter.

3. It was furthermore thought that the value of the Reports could increase by the introduction of previews about the further development of our science, and by an enumeration of future plans and projects.

4. It was further decided no longer to publish the detailed lists of Commission members since these lists are already published in Transactions XIIIB with the subsequent corrections listed in the various issues of the Information Bulletin.

These suggestions were found acceptable by many IAU members but not by all of them. The opinion was even expressed "that the new form of the Reports may make future volumes of less permanent value than Volume XIIIA, which will be the last one to attempt a full coverage of astronomy" (Observatory, 89, 240, 1969). The reader is also referred to the introduction to the report of Commission 12.

Whether the value of the present Reports is less than that of previous ones is a matter to be decided by its users. Clearly, the precise form of the Reports needs further definition in certain respects, and some more experimenting may continue to be desirable. However, it is my personal belief, based on the reading of the present Commission Reports, that by intelligent reduction of the available 
material, and by carefully separating the essential-from the trivial, the Commission Presidents have generally succeeded in presenting a more condensed, but yet complete coverage of the whole field of astronomy in all its fascinating aspects, a review that, in certain respects, may even be more balanced than some of the previous Reports, and certainly not less in value than would have been the case with the inclusion of more, but perhaps less important details and references. That each report reflects the personal style of its author(s) is one of their traditional and charming aspects.

We wish to express our very sincere thanks to the Commission Presidents and their co-workers for the way they have interpreted our suggestions, and for so strictly observing the deadline for submission of the manuscripts. Our thanks are also due to the printer and publisher of this Volume, Mr A. Reidel and his staff, for their excellent and always pleasant cooperation.

C. DE JAGER

Assistant General Secretary

Utrecht

January 1970 


\section{CONTENTS}

4. Ephemerides (Ephémérides) 1

- Reports of the Directors of the National Ephemerides 5

5. Documentation $\quad 11$

6. Astronomical Telegrams (Télégrammes Astronomiques) 15

7. Celestial Mechanics (Mécanique Céleste) 19

8. Positional Astronomy (Astronomie de Position) 39

9. Instruments et Techniques (Instruments and Techniques) 53

- Groupe de Travail sur la Qualité des Images et le Choix des Sites 66

- Groupe de Travail sur l'Emploi en Astronomie des Récepteurs Photo-

10. Solar Activity (Activité Solaire)

12. Radiation and Structure of the Solar Atmosphere

- Working Group on Central Line Intensities $\quad 123$

- Working Group on Solar Eclipses 123

14. Données Spectroscopiques Fondamentales (Fundamental Spectroscopic Data) 125

$\begin{array}{ll}\text { - Committee 1: Standards of Wavelengths } & 125\end{array}$

- Committee 2: Transition Probabilities $\quad 127$

- Committee 3: Collision Cross Sections and Line Broadening $\quad 128$

- Committee 4: Structure of Atomic Spectra $\quad 133$

- Committee 5: Molecular Spectra $\quad 137$

15. Physical Study of Comets (L'Étude Physique des Comètes) 141

16. Physical Study of Planets and Satellites (Étude Physique des Planètes et Satellites) 153

17. La Lune (The Moon) 169

19. Rotation de la Terre (Rotation of the Earth) 177

20. Positions and Motions of Minor Planets, Comets and Satellites
(Positions et Mouvements des Petites Planètes, des Comètes et des Satellites)

21. Light of the Night-Sky (Luminescence du Ciel) 193

22. Meteors and Meteorites (Météores et Météorites) 207

- Report of the Committee on Meteorites $\quad 217$

23. Carte du Ciel 225

24. Stellar Parallaxes and Proper Motions (Parallaxes Stellaires et Mouvements Propres) 227

25. Stellar Photometry (Photométrie Stellaire) 231

26. Etoiles Doubles (Double Stars) $\quad 249$

27. Variable Stars (Étoiles Variables) $\quad 259$

- Report of the Committee on the Spectra of Variable Stars 286

- Report of the Committee on Variable Stars in Clusters 291

- Report of the Working Group on Flare Stars $\quad 297$

28. Galaxies $\quad 301$

- Working Group on the Magellanic Clouds 313

- Working Group for Research on Supernovae $\quad 316$

- Working Group on Galaxy Photometry 317

29. Stellar Spectra (Spectres Stellaires)

- Working Group on Absolute Spectrophotometry 329 
- Working Group on Line Intensity Standards

- Groupe de Travail sur les Étoiles Be

30. Radial Velocities (Vitesses Radiales)

31. Time (L'Heure)

33. Structure and Dynamics of the Galactic System

$\begin{array}{ll}\text { (Structure et Dynamique du Système Galactique) } & 357\end{array}$

- Report of the Committee of "Selected Areas"

34. Interstellar Matter and Planetary Nebulae

(Metière Interstellaire et Nébuleuses Planétaires) $\quad 387$

35. Stellar Constitution (Constitution des Étoiles)

36. Theory of Stellar Atmospheres (Théorie des Atmosphères Stellaires) 425

37. Star Clusters and Associations (Amas Stellaires et Associations) 437

38. Exchange of Astronomers (Échange des Astronomes) 451

40. Radio Astronomy (Radio Astronomie) $\quad 455$

41. History of Astronomy (Histoire de L'Astronomie) 481

42. Photometric Double Stars (Étoiles Doubles Photométriques) 491

43. Plasmas and Magnetohydrodynamics in Astrophysics

(Plasmas et magnéto-hydrodynamique en Astrophysique) 515

44. Astronomical Observations from outside the Terrestrial Atmosphere

(Observations Astronomiques au-dehors de l'Atmosphere Terrestre) 525

45. Classifications Spectrales et Indices de Couleur a Plusieurs Bandes

(Spectral Classifications and Multi-Band Colour Indices) 547

46. Teaching of Astronomy (Enseignement de l'Astronomie) 